\title{
Optimization of Conductive Thin Film Epoxy Composites Properties Using Desirability Optimization Methodology
}

\author{
C. P. Khor, Mariatti bt Jaafar, and Sivakumar Ramakrishnan \\ School of Materials and Mineral Resources Engineering, Engineering Campus, Universiti Sains Malaysia, \\ Nibong Tebal, 14300 Seberang Perai Selatan, Pulau Pinang, Malaysia
}

Correspondence should be addressed to Sivakumar Ramakrishnan; srsivakumar@usm.my

Received 2 December 2015; Accepted 26 January 2016

Academic Editor: Ling Wang

Copyright (c) 2016 C. P. Khor et al. This is an open access article distributed under the Creative Commons Attribution License, which permits unrestricted use, distribution, and reproduction in any medium, provided the original work is properly cited.

Multiwalled carbon nanotubes (MWCNTs)/epoxy thin film nanocomposites were prepared using spin coating technique. The effects of process parameters such as sonication duration (5-35 $\mathrm{min}$ ) and filler loadings (1-2 vol\%) were studied using the design of experiment (DOE). Full factorial design was used to create the design matrix for the two factors with three-level experimentation, resulting in a total of 9 runs $\left(3^{2}\right)$ of experimentation. Response surface methodology (RSM) combined with E.C. Harrington's desirability function called desirability optimization methodology (DOM) was used to optimize the multiple properties (tensile strength, elastic modulus, elongation at break, thermal conductivity, and electrical conductivity) of MWCNTs/epoxy thin film composites. Based on response surface analysis, quadratic model was developed. Analysis of variance (ANOVA), $R$-squared $(R$ $\mathrm{Sq}$ ), and normal plot of residuals were applied to determine the accuracy of the models. The range of lower and upper limits was determined in an overlaid contour plot. Desirability function was used to optimize the multiple responses of MWCNTs/epoxy thin film composites. A global solution of $12.88 \mathrm{~min}$ sonication and 1.67 vol\% filler loadings was obtained to have maximum desired responses with composite desirability of 1 .

\section{Introduction}

In the past 20 years, carbon nanotubes (CNTs) are the most exciting new materials that have been discovered. Their remarkable properties have attracted huge interest from the scientific community and industry [1]. With the good mechanical properties, a high electrical and thermal conductivity due to their graphite-like structure of CNTs, and in combination with a high aspect ratio, it allows the development of conductive polymer thin film composites using only very low filler contents in which the composites retain or improve on mechanical performance of the matrix [2]. Spin coating method is selected to produce the epoxy-based thin film instead of various thin film deposition methods such as dip coating, drop coating, capillary immersion force, and electrophoretic deposition [3]. Spin coating method is more prominent in producing high uniformity films with specific thickness. By controlling the parameters such as spin rate and viscosity of the mixture, the film in range of micron to nanometers in thickness can be easily produced [4].
However, there are various types of parameters and variables involved which may affect the thin film produced, such as sonication time and filler contents, and the list goes on. From our previous works [3-5], it is found that all these varying parameters are not being studied altogether; instead some parameters are being assumed to be constant and do not affect one another. As a result, the results shown may not be totally accurate and are biased in accordance to the assumptions made.

Design of experiment (DOE) is one widely used experimental study method on many processes in engineering. It is a statistical approach in which a mathematical model is developed through experimental runs. Besides, it provides the researchers or users with the opportunity to optimize and predict possible output based on the parameters setting $[6,7]$. Response surface methodology (RSM) is a statistical technique used for mathematical modeling and analysis of problems in which a response is influenced by multiple variables and the aim is to optimize the response [7]. RSM also helps to reduce the number of required experimental 
runs to generate statistically validated results and avoid repetition of experiment for multiple factors experiments [8]. A combination of modified formula E.C. Harrington desirability function and RSM, called desirability optimization methodology (DOM), was used to optimize the overall product quality among multiple quality properties [9]. The desirability function was used to combine multiple responses into one response called the "desirability function" by choice of value from 0 (one or more product characteristics are unacceptable) to 1 (all product characteristics are on target) [10]. The method is attractive because it is simple and intuitive.

Therefore the aim of this work is to verify the factors which have significant effects on the properties of the MWCNTs/epoxy thin film by using DOE. The optimization process was performed using RSM coupled with desirability function which is the useful method to optimize multiple responses. The functional relationships between the independent variables such as sonication duration and filler loadings were studied while the interactions between the input variables were clarified.

\section{Experimental}

2.1. Materials. Epoxy type $\mathrm{DER}^{\mathrm{mi}} 332$, also known by its chemical name bisphenol-A-(epichlorohydrin), from Dow Chemical Company was used in the present study. Polyetheramine D230 (BASF Corporation) was used as curing agent. MWCNTs supplied by ShenZhen Nanotech Port Co., Ltd., China, were used as conductive fillers in the epoxy resin. Lengths and outer diameters of MWCNTs are 5-15 $\mu \mathrm{m}$ and $1-2 \mu \mathrm{m}$, respectively.

\subsection{Preparation of Epoxy Thin Film Composites. Filler load-} ing varies from 1 to 2 vol $\%$ with respect to epoxy resin. Mixing of epoxy resin and fillers was done using ultrasonic agitation method. This method is more efficient at dispersing particles into viscous systems compared with other techniques, such as conventional stirring [11]. The mixtures were sonicated at different sonication duration at room temperature as shown in Table 1 . Then, curing agent was added at a ratio of $100: 32$ by weight. They were further sonicated for 10 minutes, followed by degassing in a vacuum oven for 10 minutes to remove entrapped air. The final mixtures were then ready for the spin coating process, which was carried out using DeskTop Precision Spin Coater model G3P-12. Speed of spinning was $250-750 \mathrm{rpm}$. The resulting thin films were cured at $80^{\circ} \mathrm{C}$ for 2 hours.

2.3. Characterization Techniques. The tensile properties (tensile strength, elastic modulus, and elongation at break) of the composite systems were determined using Instron 3366 according to ASTM D882-02 with the crosshead of $1 \mathrm{~mm} / \mathrm{min}$. In order to minimize the error, five specimens were averaged to collect the results. Thermal conductivity of epoxy thin film composites was determined using a hot disk thermal constant analyzer (TPS 2500S Thermal Conductivity System) according to ISO 22007-2:2008. The testing time for
TABLE 1: Experimental range and level of the respective independent variables.

\begin{tabular}{lccccc}
\hline \multirow{2}{*}{ Variable } & \multirow{2}{*}{ Notation } & Unit & \multicolumn{3}{c}{ Level } \\
& & & -1 & 0 & 1 \\
\hline Sonication duration & $A$ & $\min$ & 5 & 20 & 35 \\
Filler loadings & $B$ & vol\% & 1 & 1.5 & 2 \\
\hline
\end{tabular}

each sample was varied from $40 \mathrm{~s}$ to $70 \mathrm{~s}$ and operating power from $1 \mathrm{~W}$ to $2 \mathrm{~W}$. Electrical resistances of thin film samples were measured using AdvanTest R8340 Ultra High Resistance Meter. Voltage of $10 \mathrm{~V}$ was used.

2.4. Statistical Analysis Using Design of Experiments. The Minitab software, version 16.2.1 based on full factorial design, was used to perform the design matrices for the experiment. The Minitab software based on RSM was used to perform the statistical analysis and generate the regression model. The variables in this study included two numerical factors of sonication duration $(A)$ and filler loadings $(B)$.

Table 1 shows the ranges of the independent variables and experimental design levels which were used in this work. Since the experimental design was developed based on full factorial design involving two factors with three levels and one repetition of experiment, therefore the number of experimental runs was 9 runs in accordance to $3^{2}$. Multiple responses were investigated simultaneously and they were tensile strength, elastic modulus, elongation at break, thermal conductivity, and electrical conductivity of the MWCNTs/epoxy thin film composites.

Table 2 shows the complete experimental design and actual responses of the experiments employed in this study. The actual responses such as tensile strength, elastic modulus, and elongation at break, thermal conductivity, and electrical conductivity were denoted by $Y 1, Y 2, Y 3, Y 4$, and $Y 5$, respectively. These data were used as input into the DOE software for analysis to determine the model equation. The adequacy of the models was further justified through the ANOVA, regression analysis, and normal plot of residuals. The mathematical models for the desired responses as a function of selected variables were developed by applying the multiple regression analysis on the experimental data. The general quadratic equation model is stated by

$$
Y=\beta_{0}+\sum_{i=1}^{k} \beta_{i} x_{i}+\sum_{i=1}^{k} \beta_{i i} x_{i}^{2}+\sum_{i<j}^{k} \beta_{i j} x_{i} x_{j}+\varepsilon
$$

where $Y$ represents the responses (dependent variables), $\beta_{0}$ is the constant coefficient, $\beta_{i}, \beta_{i i}$, and $\beta_{i j}$ are coefficients for the linear, quadratic, and interaction effects, respectively, $x_{i}$ and $x_{j}$ are factors (independent variables), and $\varepsilon$ is the standard error.

The quality of developed models was determined by the coefficients of determination $\left(R^{2}\right)$ while the analysis of variance (ANOVA) was used to evaluate the statistical significance of the model. 
TABLE 2: The experimental design and actual responses of MWCNTs/epoxy thin film composites.

\begin{tabular}{|c|c|c|c|c|c|c|c|}
\hline \multirow[b]{2}{*}{ Run number } & \multicolumn{2}{|c|}{ Variables in decoded levels } & \multicolumn{5}{|c|}{ Actual responses } \\
\hline & $\begin{array}{c}\text { Sonication } \\
\text { duration (min) } \\
A\end{array}$ & $\begin{array}{c}\text { Filler } \\
\text { loadings (vol\%) } \\
B\end{array}$ & $\begin{array}{c}\text { Tensile strength } \\
(\mathrm{MPa}) \\
Y 1\end{array}$ & $\begin{array}{c}\text { Elastic modulus } \\
(\mathrm{MPa}) \\
Y 2\end{array}$ & $\begin{array}{c}\text { Elongation at } \\
\text { break (\%) } \\
\text { Y3 }\end{array}$ & $\begin{array}{c}\text { Thermal } \\
\text { conductivity } \\
(\mathrm{W} / \mathrm{mK}) \\
Y 4\end{array}$ & $\begin{array}{c}\begin{array}{c}\text { Electrical } \\
\text { conductivity } \\
\left(\mathrm{ohm}^{-1} \mathrm{~m}^{-1}\right) \\
Y 5\end{array} \\
\end{array}$ \\
\hline 1 & 35 & 1.0 & 48.31 & 2140.80 & 2.91 & 0.05995 & $2.75 \times 10^{-10}$ \\
\hline 2 & 35 & 1.5 & 53.42 & 2221.40 & 2.90 & 0.06345 & $3.94 \times 10^{-10}$ \\
\hline 3 & 5 & 1.0 & 22.74 & 1217.66 & 2.41 & 0.05518 & $2.15 \times 10^{-8}$ \\
\hline 4 & 20 & 1.0 & 40.65 & 1779.00 & 2.88 & 0.05669 & $7.62 \times 10^{-6}$ \\
\hline 5 & 5 & 2.0 & 20.36 & 1163.40 & 2.19 & 0.09750 & $4.71 \times 10^{-8}$ \\
\hline 6 & 35 & 2.0 & 35.79 & 2240.00 & 2.45 & 0.07189 & $8.26 \times 10^{-10}$ \\
\hline 7 & 5 & 1.5 & 36.71 & 1800.00 & 2.42 & 0.08550 & $2.96 \times 10^{-8}$ \\
\hline 8 & 20 & 1.5 & 52.24 & 2202.40 & 2.83 & 0.08732 & $6.35 \times 10^{-6}$ \\
\hline 9 & 20 & 2.0 & 50.96 & 2493.40 & 2.79 & 0.10050 & $1.11 \times 10^{-5}$ \\
\hline
\end{tabular}

TABLE 3: ANOVA for tensile strength (Y1).

\begin{tabular}{lccccc}
\hline Source & Sum of squares & DF & Mean square & $F$-value & $p$ value \\
\hline Model & 1100.88 & 5 & 220.18 & 5.06 & 0.106 \\
$A$ & 555.07 & 1 & 555.07 & 12.74 & 0.038 \\
$B$ & 3.51 & 1 & 3.51 & 0.08 & 0.795 \\
$A^{2}$ & 275.11 & 1 & 275.11 & 6.32 & 0.087 \\
$B^{2}$ & 241.49 & 1 & 241.49 & 5.54 & 0.099 \\
$A B$ & 25.70 & 1 & 25.70 & 0.59 & 0.498 \\
Residual & 130.66 & 3 & 43.55 & & \\
Cor total & 1231.54 & 8 & & & \\
\hline
\end{tabular}

TABLE 4: ANOVA for elastic modulus (Y2).

\begin{tabular}{lccccc}
\hline Source & Sum of squares & DF & Mean square & $F$-value & $p$ value \\
\hline Model & $1.45 \times 10^{6}$ & 5 & $2.90 \times 10^{5}$ & 2.90 & 0.205 \\
$A$ & $9.77 \times 10^{5}$ & 1 & $9.77 \times 10^{5}$ & 9.78 & 0.052 \\
$B$ & $9.61 \times 10^{4}$ & 1 & $9.61 \times 10^{4}$ & 0.96 & 0.399 \\
$A^{2}$ & $2.61 \times 10^{5}$ & 1 & $2.61 \times 10^{5}$ & 2.61 & 0.205 \\
$B^{2}$ & $1.11 \times 10^{5}$ & 1 & $1.11 \times 10^{5}$ & 1.11 & 0.369 \\
$A B$ & $5.89 \times 10^{3}$ & 1 & $5.89 \times 10^{3}$ & 0.06 & 0.824 \\
Residual & $3.00 \times 10^{5}$ & 3 & $9.99 \times 10^{4}$ & & \\
Cor total & $1.75 \times 10^{6}$ & 8 & & & \\
\hline
\end{tabular}

\section{Results and Discussion}

\subsection{Analysis and Model Fitting for Responses}

3.1.1. ANOVA. The ANOVA for the quadratic model for tensile strength (Y1), elastic modulus (Y2), elongation at break (Y3), thermal conductivity (Y4), and electrical conductivity (Y5) are summarized in Tables 3, 4, 5, 6, and 7.

Table 3 shows that the "Model F-value" of 5.06 for $Y 1$ implies that the model is not significant relative to noise. There is $10.6 \%$ chance that a large "Model $F$-value" could occur due to noise. It is noted that $p$ value less than 0.05 indicates model terms are significant. In this case, the significant model term for $Y 1$ is $A$ (sonication duration) since
TABLE 5: ANOVA for elongation at break (Y3).

\begin{tabular}{lccccc}
\hline Source & Sum of squares & DF & Mean square & $F$-value & $p$ value \\
\hline Model & 0.56 & 5 & 0.11 & 8.87 & 0.051 \\
$A$ & 0.26 & 1 & 0.26 & 20.35 & 0.020 \\
$B$ & 0.099 & 1 & 0.099 & 7.85 & 0.068 \\
$A^{2}$ & 0.16 & 1 & 0.16 & 13.05 & 0.036 \\
$B^{2}$ & 0.025 & 1 & 0.025 & 1.98 & 0.254 \\
$A B$ & 0.014 & 1 & 0.014 & 1.14 & 0.363 \\
Residual & 0.038 & 3 & 0.013 & & \\
Cor total & 0.60 & 8 & & & \\
\hline
\end{tabular}

TABLE 6: ANOVA for thermal conductivity (Y4).

\begin{tabular}{lccccc}
\hline Source & Sum of squares & DF & Mean square & $F$-value & $p$ value \\
\hline Model & $2.37 \times 10^{-3}$ & 5 & $4.73 \times 10^{-4}$ & 9.41 & 0.047 \\
$A$ & $3.07 \times 10^{-4}$ & 1 & $3.07 \times 10^{-4}$ & 6.10 & 0.090 \\
$B$ & $1.60 \times 10^{-3}$ & 1 & $1.60 \times 10^{-3}$ & 31.91 & 0.011 \\
$A^{2}$ & $1.71 \times 10^{-4}$ & 1 & $1.71 \times 10^{-4}$ & 3.41 & 0.162 \\
$B^{2}$ & $5.28 \times 10^{-5}$ & 1 & $5.28 \times 10^{-5}$ & 1.05 & 0.381 \\
$A B$ & $2.31 \times 10^{-4}$ & 1 & $2.31 \times 10^{-4}$ & 4.59 & 0.122 \\
Residual & $1.51 \times 10^{-4}$ & 3 & $5.02 \times 10^{-5}$ & & \\
Cor total & $2.52 \times 10^{-3}$ & 8 & & &
\end{tabular}

that it has $p$ value of 0.038 which is less than 0.05 . The $p$ value in fact is actually the smallest level of significance, which could be used to reject the null hypothesis, $H_{0}$. It provides a way of testing the relationship between the predictor and the response. The smaller the value is, the more significant its corresponding coefficient and the contribution towards the response variable are [8].

According to Tables 4 and 5, it can be seen that the "Model F-value" for $Y 2$ and $Y 3$ is 2.90 and 8.87. These imply that the models are not significantly relative to noise. There are $20.5 \%$ and $5.1 \%$ chances that a "Model F-value" this large could occur due to noise, respectively. In these cases, there are no significant model terms for $Y 2$ and at the 
TABLE 7: ANOVA for electrical conductivity (Y5).

\begin{tabular}{lccccc}
\hline Source & Sum of squares & DF & Mean square & $F$-value & $p$ value \\
\hline Model & $1.43 \times 10^{-10}$ & 5 & $2.86 \times 10^{-11}$ & 10.70 & 0.040 \\
$A$ & $1.56 \times 10^{-15}$ & 1 & $1.56 \times 10^{-15}$ & 0.00 & 0.982 \\
$B$ & $2.05 \times 10^{-12}$ & 1 & $2.05 \times 10^{-12}$ & 0.77 & 0.446 \\
$A^{2}$ & $1.39 \times 10^{-10}$ & 1 & $1.39 \times 10^{-10}$ & 51.99 & 0.005 \\
$B^{2}$ & $2.02 \times 10^{-12}$ & 1 & $2.02 \times 10^{-12}$ & 0.75 & 0.449 \\
$A B$ & $1.57 \times 10^{-16}$ & 1 & $1.57 \times 10^{-16}$ & 0.00 & 0.994 \\
Residual & $8.03 \times 10^{-12}$ & 3 & $2.68 \times 10^{-12}$ & & \\
Cor total & $1.51 \times 10^{-10}$ & 8 & & & \\
\hline
\end{tabular}

TABLE 8: Response surface regression for tensile strength (Y1).

\begin{tabular}{lcccc}
\hline Term & Coef. & SE Coef. & $t$ & $p$ \\
\hline Const. & 55.2756 & 4.919 & 11.237 & 0.002 \\
$A$ & 9.6183 & 2.694 & 3.570 & 0.038 \\
$B$ & -0.7650 & 2.694 & -0.284 & 0.795 \\
$A^{2}$ & -11.7283 & 4.667 & -2.513 & 0.087 \\
$B^{2}$ & -10.9883 & 4.667 & -2.355 & 0.100 \\
$A B$ & -2.5350 & 3.300 & -0.768 & 0.498 \\
\hline \multicolumn{5}{c}{$S=6.59950$, PRESS $=1494.39$} \\
\end{tabular}

same time the significant model terms for $Y 3$ are $A$ and $A^{2}$ (sonication duration $*$ sonication duration). The $p$ value for $A$ is 0.02 while being 0.036 for $A^{2}$. Both of these factor term and respective quadratic term had the largest effect on the elongation at break at $95 \%$ confidence level of significance as indicated by the lowest $p$ value $(<0.05)$ and relatively high $F$ value.

Meanwhile, it can be observed that "Model $F$-value" of 9.41 and 10.70 implies the model is significant for $Y 4$ and $Y 5$ from Tables 6 and 7. There are only $4.7 \%$ and $4.0 \%$ chances that a "Model $F$-value" this large could occur due to noise for each case. $B$ (filler loadings) is the significant model term for $Y 4$ while $A^{2}$ is the significant model term for $Y 5$ as they have $p$ value of 0.011 and 0.006 , respectively, which is less than 0.05 .

3.1.2. Response Surface Regression Analysis. Response surface regression is used to examine the relationship between a response and a set of quantitative experimental variables or factors. The regression analysis for each response was done using coded units and summarized in Tables 8-12, respectively.

Table 8 shows that the $R$-Sq of the model for $Y 1$ is $89.39 \%$ which means that $89.39 \%$ of the total variation in the results was attributed to the independent variables investigated. $R$-Sq is a criterion evaluation in which the correctness of the model in explaining the model is evaluated by its $R$-Sq value. In other words, the closer the $R$-Sq value is to $100 \%$ shows that the model will give better predicted values which are closer to the actual values for the response. However, $R$-Sq can be made artificially high by including too many terms in the regression model. If unnecessary predictors are added to the model, the
TABLE 9: Response surface regression for elastic modulus (Y2).

\begin{tabular}{lcccc}
\hline Term & Coef. & SE Coef. & $t$ & $p$ \\
\hline Const. & 2315.30 & 235.6 & 9.826 & 0.002 \\
$A$ & 403.52 & 129.1 & 3.127 & 0.052 \\
$B$ & 126.56 & 129.1 & 0.981 & 0.399 \\
$A^{2}$ & -361.06 & 223.5 & -1.615 & 0.205 \\
$B^{2}$ & -235.56 & 223.5 & -1.054 & 0.369 \\
$A B$ & 38.36 & 158.1 & 0.243 & 0.824 \\
\hline \multicolumn{5}{c}{$S=316.129$, PRESS $=3518810$} \\
\end{tabular}

TABLE 10: Response surface regression for elongation at break (Y3).

\begin{tabular}{lcccc}
\hline Term & Coef. & SE Coef. & $t$ & $p$ \\
\hline Const. & 2.90778 & 0.08364 & 34.765 & 0.000 \\
$A$ & 0.20667 & 0.04581 & 4.511 & 0.020 \\
$B$ & -0.12833 & 0.04581 & -2.801 & 0.068 \\
$A^{2}$ & -0.28667 & 0.07935 & -3.613 & 0.036 \\
$B^{2}$ & -0.11167 & 0.07935 & -1.407 & 0.254 \\
$A B$ & -0.06000 & 0.05611 & -1.069 & 0.363 \\
\hline \multicolumn{5}{c}{$S=0.112217$, PRESS $=0.395874$} \\
\end{tabular}

TABLE 11: Response surface regression for thermal conductivity (Y4).

\begin{tabular}{lcccc}
\hline Term & Coef. & SE Coef. & $t$ & $p$ \\
\hline Const. & 0.08493 & 0.005283 & 16.077 & 0.001 \\
$A$ & -0.00715 & 0.002893 & -2.471 & 0.090 \\
$B$ & 0.01635 & 0.002893 & 5.649 & 0.011 \\
$A^{2}$ & -0.00926 & 0.00501 & -1.847 & 0.162 \\
$B^{2}$ & -0.00514 & 0.00501 & -1.025 & 0.381 \\
$A B$ & -0.00756 & 0.003544 & -2.143 & 0.121 \\
\hline \multicolumn{5}{c}{$S=0.00708733, \mathrm{PRESS}=0.00177598$} \\
\end{tabular}

TABLE 12: Response surface regression for electrical conductivity (Y5).

\begin{tabular}{lcccc}
\hline Term & Coef. & SE Coef. & $t$ & $p$ \\
\hline Const. & 0.000008 & 0.000001 & 6.305 & 0.008 \\
$A$ & -0.00000 & 0.000001 & -0.024 & 0.982 \\
$B$ & 0.000001 & 0.000001 & 0.875 & 0.446 \\
$A^{2}$ & -0.000008 & 0.000001 & -7.211 & 0.005 \\
$B^{2}$ & 0.000001 & 0.000001 & 0.869 & 0.449 \\
$A B$ & -0.00000 & 0.000001 & -0.008 & 0.994 \\
\hline \multicolumn{5}{c}{} \\
\hline
\end{tabular}

$R$-Sq increases even if no additional information about the response is gained.

Meanwhile, $Y 2, Y 3, Y 4$, and $Y 5$ have $R$-Sq values of $82.87 \%, 93.67 \%, 94.01 \%$, and $94.69 \%$, respectively. Since the $R$-Sq values for five responses are reasonably high, it is said that the accuracy of models is high. 


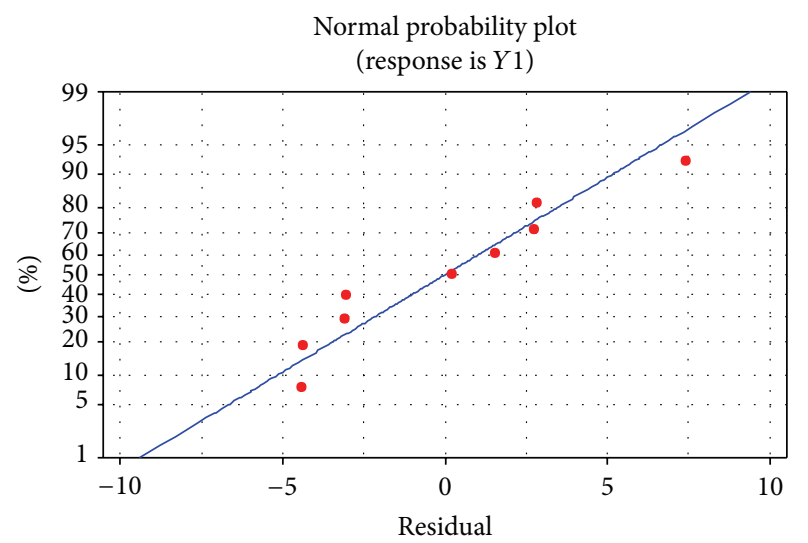

FIGURE 1: Normal probability plot for tensile strength $(Y 1)$ response.

Also, from the response surface regression analysis the final empirical model in terms of coded factors can be obtained. For each case, the models are as listed:

$$
\begin{aligned}
Y 1= & 55.28+9.62 A-0.76 B-11.73 A^{2}-10.99 B^{2} \\
& -2.54 A B \\
Y 2= & 2315.30+403.52 A+126.56 B-361.06 A^{2} \\
& -235.56 B^{2}+38.36 A B \\
Y 3= & 2.91+0.21 A-0.13 B-0.29 A^{2}-0.11 B^{2} \\
& -0.06 A B, \\
Y 4= & 0.085-7.148 \times 10^{-3} A+0.016 B-9.258 \\
& \times 10^{-3} A^{2}-5.138 \times 10^{-3} B^{2}-7.595 \\
& \times 10^{-3} A B, \\
Y 5= & 7.69 \times 10^{-6}-1.61 \times 10^{-8} A+5.84 \times 10^{-7} B \\
& -8.34 \times 10^{-6} A^{2}+1.01 \times 10^{-6} B^{2}-6.26 \\
& \times 10^{-9} A B .
\end{aligned}
$$

3.1.3. Normal Plot of Residuals. A good estimated regression model will explain the variation of the dependent variable in the sample. Normal plots have the residuals being plotted versus their expected values when the distribution is normal. Residuals are the difference between the observed and the fitted response value. The residuals from the analysis should be normally distributed. In practice, for balanced or nearly balanced designs or for data with a large number of observations, moderate departures from normality do not seriously affect the results.

The normal plot of residuals of the two variables (sonication duration and filler loadings) for tensile strength is plotted in Figure 1. From Figure 1 it can be seen that the residuals are plotted around the straight line which indicates that the

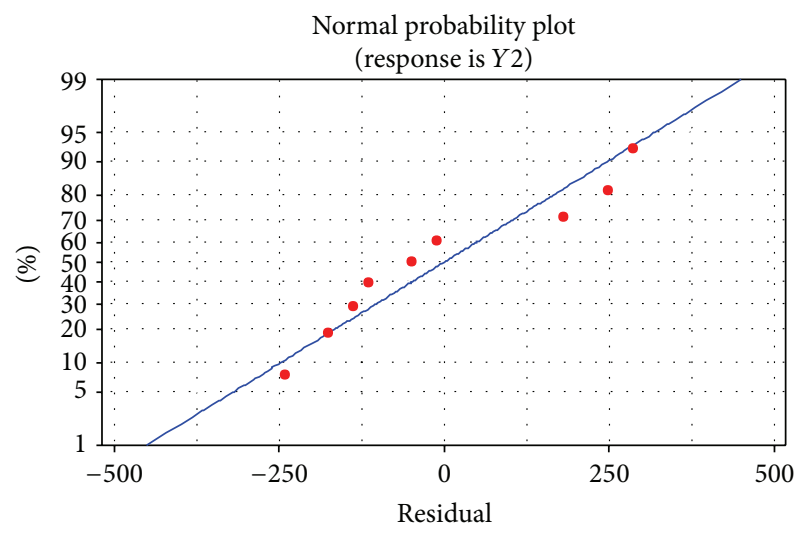

FIgURE 2: Normal probability plot for elastic modulus (Y2) response.

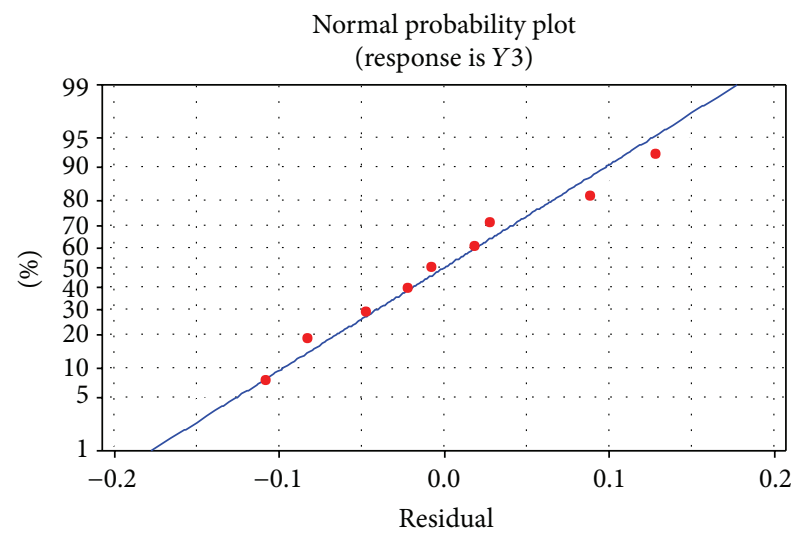

FIGURE 3: Normal probability plot for elongation at break (Y3) response.

residuals are normally distributed. Similarly, from Figures 25 , residuals for $Y 2, Y 3, Y 4$, and $Y 5$ can be observed which are plotted approximately along the straight line as $Y 1$. Hence, it can be said that the normality assumption is satisfied for five of the responses in this study. Therefore, there is no evidence of nonnormality, skewness, outliers, or unidentified variables that exist.

3.2. Numerical Optimization. Numerical optimization was provided by the DOE method using Minitab software to find out the optimum combinations of parameters to fulfill the desired requirements. The ultimate goal of this optimization was to obtain the maximum responses that simultaneously satisfied all the variables properties.

3.2.1. Desirability Optimization Methodology. In order to simultaneously optimize several responses, each of the transformed responses, called $d_{i}$, is a transformation of the response variable to a 0 to 1 scale which are combined using the geometric mean to create the overall desirability $(D)$ :

$$
D=\sqrt[n]{d_{1} * d_{2} * d_{3} * \cdots * d_{n}} .
$$




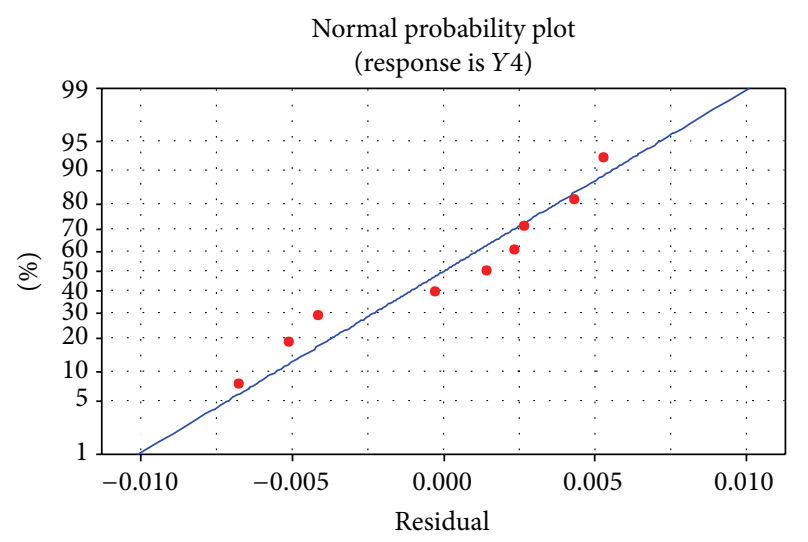

FIGURE 4: Normal probability plot for thermal conductivity (Y4) response.

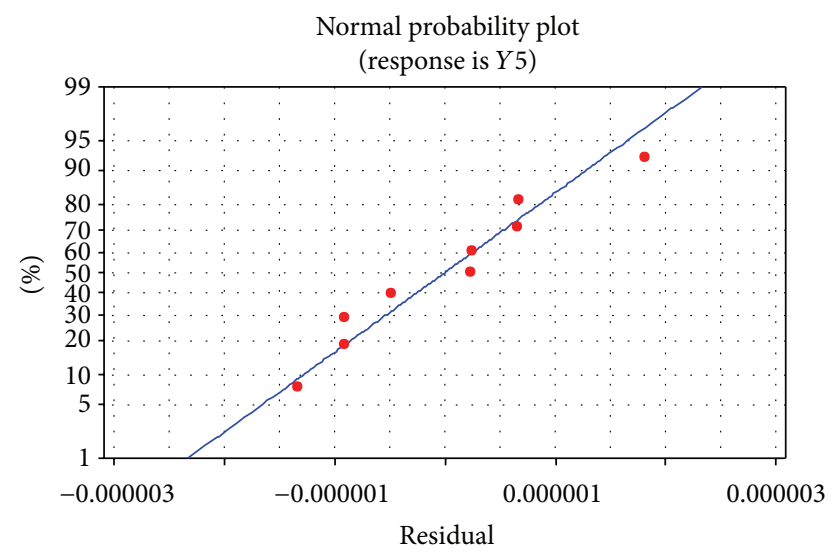

FIGURE 5: Normal probability plot for electrical conductivity (Y5) response.

Using the product of the desirability functions assures that if any single desirability is 0 (undesirable), the overall desirability is 0 . Therefore, the simultaneous optimization of several responses has been reduced to optimizing a single response: the overall desirability, $D$ [12]. To perform the response optimization, firstly the range and the target of the responses are needed to be selected. An overlaid contour plot is plotted in order to find the range of lower and upper bounds for response optimization as shown in Figure 6.

Overlaid contour plot is a plot that places the contours of each response on top of each other in a single graph. Each set of contours defines the boundaries of acceptable response values. The solid contour line is the lower bound and the dotted contour is the upper bound. The contours of each response are displayed in a different color. The white region in the overlaid contour plot is the feasible region. It is an area such that the acceptable values for each response are between their respective contours. The possible combination of parameter settings can be obtained within the feasible region.

In order to produce MWCNTs/epoxy thin film composites acquired with acceptable properties which are also known as responses, the ranges of the responses are needed

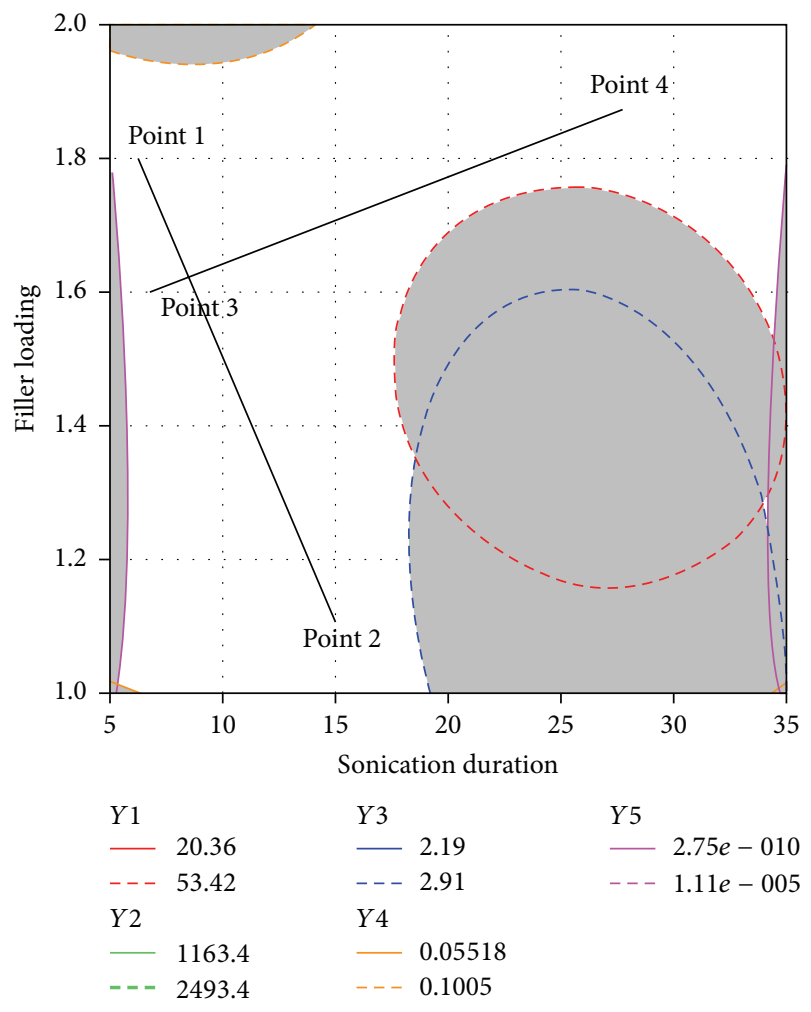

FIGURE 6: Overlaid contour plot for responses.

to be determined. In this study, two gradient lines, namely, Gradient 1 and Gradient 2, were drawn on the feasible region. However, the gradient lines have to be carefully drawn so that they do not touch the color region. The gradient line which connects points 1 and 2 is Gradient 1 while for points 3 and 4 the line is Gradient 2. Table 13 summarizes the data for parameter settings and responses at four different points, respectively. Thus, the range of lower and upper bound for Gradient 1 can be set. By comparing both points 1 and 2, those having smaller values are selected as lower bound and vice versa. At the meantime, the center of the range for each response is set as the target. Similarly, the same thing goes for Gradient 2. With the range of lower and upper bounds obtained, response optimizer in the Minitab software was used to conduct the optimization for responses. A global solution for each gradient was obtained. Global solution is the best combination of factor setting for achieving the desired responses. The optimization plots for multiple responses stated are plotted in Figures 7 and 8.

From Figures 7 and 8, the single desirability for all the responses is 1 . This means that the predicted responses are the closest to the target requirements. Also, the composite desirability of MWCNTs/epoxy thin film composites for both gradients is 1 . This reflects that it has equal relative importance of the responses. The red solid lines indicate the global solution for the gradient. Meanwhile, the dotted blue lines represent the predicted responses. In the interpretation of optimization plot, both gradients have the same pattern of curvatures. 
TABLE 13: Values of the four points on Gradients 1 and 2.

\begin{tabular}{lcccc}
\hline \multirow{2}{*}{ Factors } & \multicolumn{2}{c}{ Gradient 1 } & \multicolumn{2}{c}{ Gradient 2 } \\
& Point 1 & Point 2 & Point 3 & Point 4 \\
\hline Sonication duration & 6.167 & 15.136 & 6.570 & 27.734 \\
Filler loadings & 1.800 & 1.108 & 1.599 & 1.874 \\
Y1 & 33.409 & 44.140 & 37.131 & 49.406 \\
Y2 & 1605.9 & 1912.7 & 1673.6 & 2404.9 \\
Y3 & 2.389 & 2.827 & 2.474 & 2.756 \\
Y4 & 0.0958 & 0.0684 & 0.0883 & 0.0852 \\
Y5 & $1.33 \times 10^{-6}$ & $6.97 \times 10^{-6}$ & $1.17 \times 10^{-6}$ & $6.46 \times 10^{-6}$ \\
\hline
\end{tabular}

\begin{tabular}{|c|c|c|}
\hline $\begin{array}{cc}\text { Optimal } & \\
D & \text { High } \\
1.0000 & \text { Cur } \\
& \text { Low }\end{array}$ & $\begin{array}{c}\text { Sonication } \\
35.0 \\
{[12.8788]} \\
5.0\end{array}$ & $\begin{array}{c}\text { Filler I } \\
2.0 \\
{[1.6723]} \\
1.0\end{array}$ \\
\hline $\begin{array}{c}\text { Composite } \\
\text { desirability } \\
1.0000\end{array}$ & & \\
\hline $\begin{array}{c}Y 1 \\
\text { Maximum } \\
y=46.9123 \\
d=1.0000\end{array}$ & & \\
\hline $\begin{array}{c}Y 2 \\
\text { Maximum } \\
y=2051.7203 \\
d=1.0000\end{array}$ & & \\
\hline $\begin{array}{c}Y 3 \\
\text { Maximum } \\
y=2.6974 \\
d=1.0000\end{array}$ & & \\
\hline $\begin{array}{c}Y 4 \\
\text { Maximum } \\
y=0.0925 \\
d=1.0000\end{array}$ & & \\
\hline $\begin{array}{c}Y 5 \\
\text { Maximum } \\
y=0.0 \\
d=1.0000\end{array}$ & & \\
\hline
\end{tabular}

FIgURE 7: Optimization plot of multiple responses for Gradient 1.

For the factor of sonication duration, increasing the sonication duration increases the responses of $Y 1, Y 2, Y 3$, and $Y 5$ but decreases $Y 4$. The opposite way goes for $Y 1, Y 2$, $Y 3$, and $Y 5$ when decreasing the sonication duration. $Y 4$ can be observed at its optimal point at $11.97 \mathrm{~min}$ and $12.88 \mathrm{~min}$ sonication duration. Meanwhile, increasing the filler loadings increases $Y 4$ and $Y 5$ but reduces $Y 1, Y 2$, and $Y 3$. Decreasing the filler loadings increases $Y 1, Y 2$, and $Y 3$ but reduces $Y 4$ and $Y 5$. However, $Y 2$ is observed to reach its optimal point at $1.67 \mathrm{vol} \%$ filler loadings.

Among the two possible combinations of operating condition, global solution of Gradient 2 is chosen as it produces

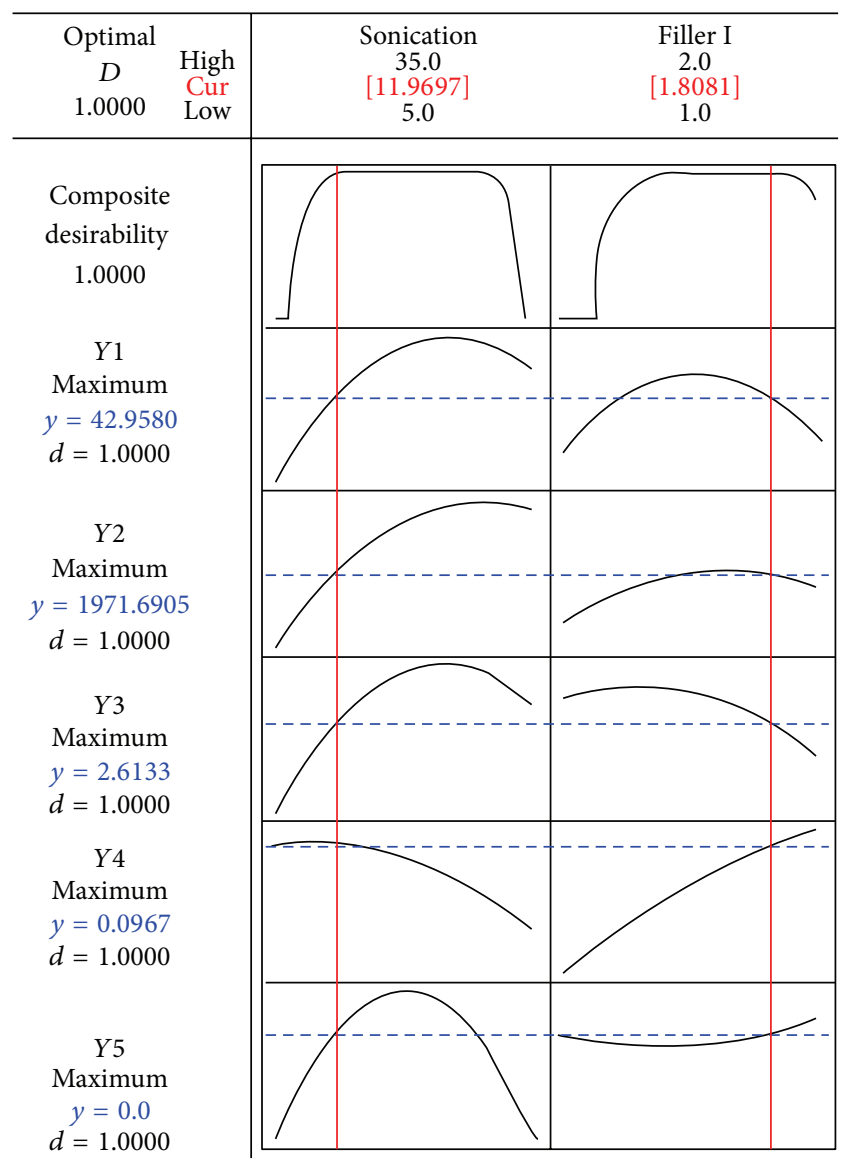

FIGURE 8: Optimization plot of multiple responses for Gradient 2.

composite with higher predicted responses than that of Gradient 1. Besides that, Gradient 2 has lower filler loadings than Gradient 1 and just a slight difference in the sonication duration. Lower filler loadings will eventually reduce the cost of composite produced. Hence, the global solution of $12.88 \mathrm{~min}$ sonication duration and $1.67 \mathrm{vol} \%$ filler loadings is chosen as higher sonication duration and lower loadings provide better dispersion of MWCNTs into the epoxy matrix.

After optimization using the proposed method in the above work, the properties of the MWCNTs/epoxy thin film nanocomposites increased $17 \%$ for tensile strength (MPa), 7\% for elastic modulus (MPa), 2.1\% for elongation at break (\%), $22.8 \%$ for thermal conductivity $(\mathrm{W} / \mathrm{mK})$, and no changes in electrical conductivity $\left(\mathrm{ohm}^{-1} \mathrm{~m}^{-1}\right)$.

\section{Conclusion}

This study showed the use of statistical design to optimize the multiple properties of the MWCNTs/epoxy thin film composites. The optimization was carried out to investigate the effects of parameters (sonication duration and filler loadings) on the thin film composites properties. Based on the optimization through the desirability optimization approach, the optimal parameter setting was achieved with reinforcing $1.67 \mathrm{vol} \%$ MWCNTs by ultrasonication for $12.88 \mathrm{~min}$ 
to disperse MWCNTs in epoxy matrix. A global solution of $12.88 \mathrm{~min}$ sonication and 1.67 vol\% filler loadings was obtained to have maximum desired responses with composite desirability of 1 . The significant amount of improvement has been made in the results of MWCNTs/epoxy thin film nanocomposites where $17 \%$ for tensile strength $(\mathrm{MPa}), 7 \%$ for elastic modulus ( $\mathrm{MPa}), 2.1 \%$ for elongation at break (\%), and $22.8 \%$ for thermal conductivity $(\mathrm{W} / \mathrm{mK})$ are as tangible increment in each response except in electrical conductivity $\left(\mathrm{ohm}^{-1} \mathrm{~m}^{-1}\right)$ without any changes.

\section{Conflict of Interests}

The authors declare that there is no conflict of interests regarding the publication of this paper.

\section{Acknowledgments}

This study was supported by Research University Grant (814055) from the Universiti Sains Malaysia and the Ministry of Science, Technology, and Innovation (MOSTI).

\section{References}

[1] P. J. F. Harris, "Carbon nanotube composites," International Materials Reviews, vol. 49, no. 1, pp. 31-43, 2004.

[2] F. H. Gojny, M. H. G. Wichmann, B. Fiedler et al., "Evaluation and identification of electrical and thermal conduction mechanisms in carbon nanotube/epoxy composites," Polymer, vol. 47, no. 6, pp. 2036-2045, 2006.

[3] R. Voo, M. Mariatti, and L. C. Sim, "Properties of epoxy nanocomposite thin films prepared by spin coating technique," Journal of Plastic Film and Sheeting, vol. 27, no. 4, pp. 331-346, 2011.

[4] E. Foo, M. Jaafar, A. Aziz, and L. C. Sim, "Properties of spin coated epoxy/silica thin film composites: effect of nano- and micron-size fillers," Composites Part A: Applied Science and Manufacturing, vol. 42, no. 10, pp. 1432-1437, 2011.

[5] W. P. Serena Saw and M. Mariatti, "Properties of synthetic diamond and graphene nanoplatelet-filled epoxy thin film composites for electronic applications," Journal of Materials Science: Materials in Electronics, vol. 23, no. 4, pp. 817-824, 2012.

[6] M. Tanco, E. Viles, and L. Pozueta, "Comparing different approaches for design of experiments (DoE)," in Advances in Electrical Engineering and Computational Science, S.-I. Ao and L. Gelman, Eds., vol. 39 of Lecture Notes in Electrical Engineering, pp. 611-621, Springer, Dordrecht, The Netherlands, 2009.

[7] D. G. Montgomery, Design and Analysis of Experiments, John Wiley \& Sons, New York, NY, USA, 2001.

[8] H. Adeli, S. H. S. Zein, S. H. Tan, and A. L. Ahmad, "Optimization of the mechanical strength properties of poly(Llactide)/multi-walled carbon nanotube scaffolds using response surface methodology," Nano: Brief Reports and Reviews, vol. 6, no. 2, pp. 113-122, 2011.

[9] G. C. A. Derringer, Balancing Act: Optimizing a Product's Properties, Quality Progress, 1994.

[10] J. C. Wei, D. L. Olson, and E. M. White, "Simultaneous optimization in process quality control via prediction-interval constrained programming," The Journal of the Operational Research Society, vol. 41, no. 12, pp. 1161-1167, 1990.

[11] Q. Wang, H. S. Xia, and C. H. Zhang, "Preparation of polymer/inorganic nanoparticles composites through ultrasonic irradiation," Journal of Applied Polymer Science, vol. 80, no. 9, pp. 1478-1488, 2001.

[12] D. J. Obermiller, Multiple Response Optimization using JMP Dow Chemical Company, Midland, Mich, USA, 2000. 


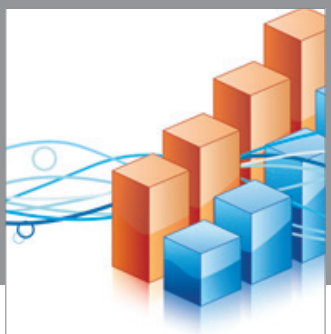

Advances in

Operations Research

vatem alat4

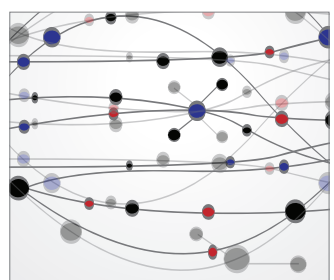

\section{The Scientific} World Journal
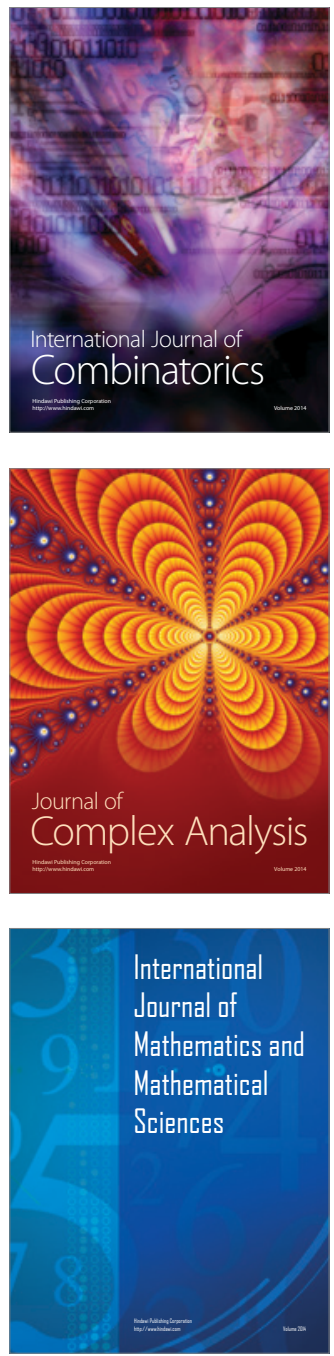
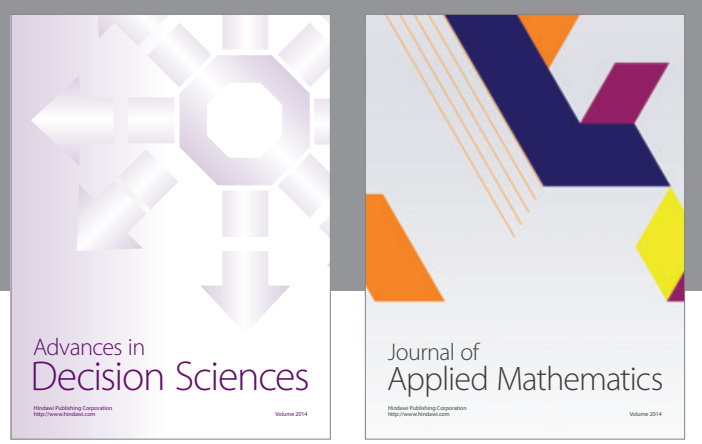

Algebra

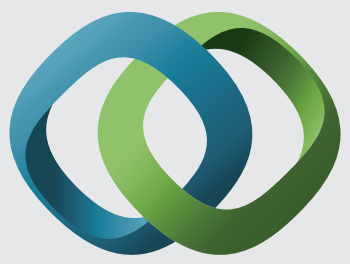

\section{Hindawi}

Submit your manuscripts at

http://www.hindawi.com
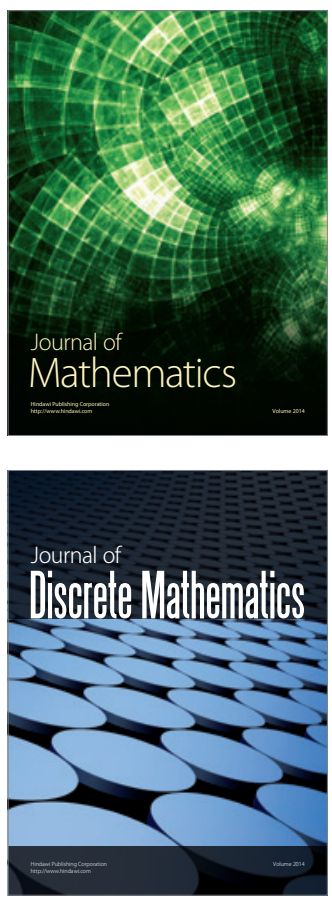

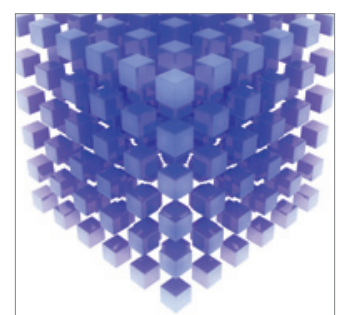

Mathematical Problems in Engineering
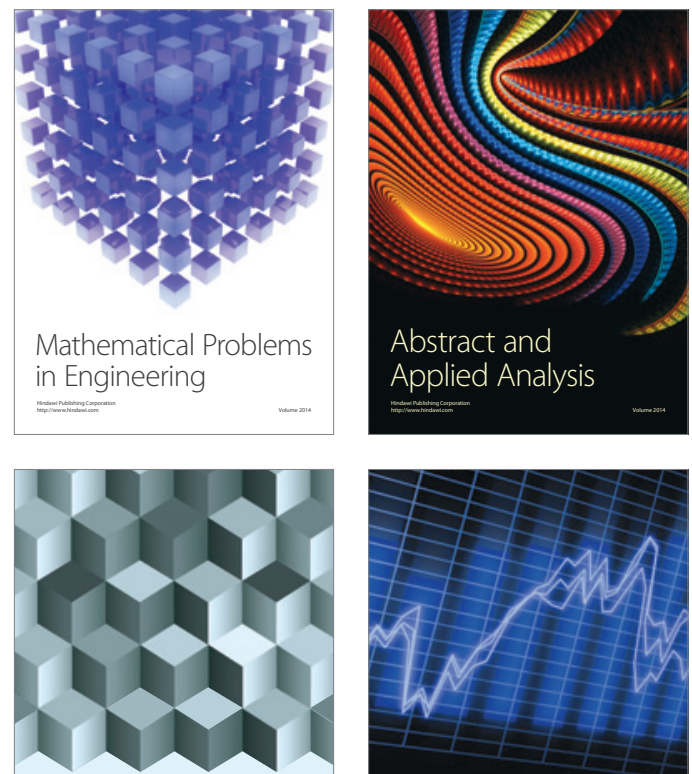

Journal of

Function Spaces

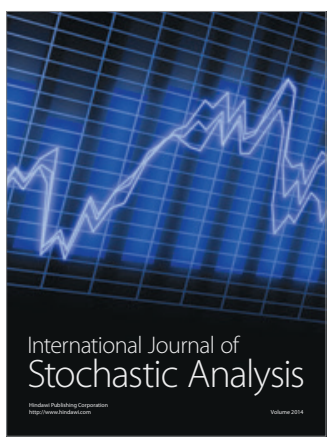

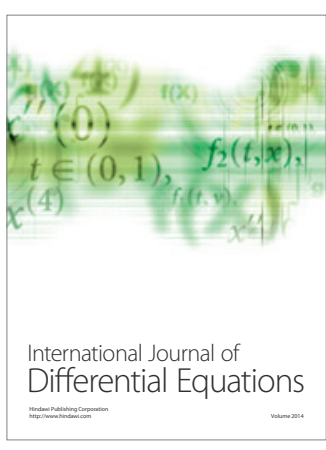
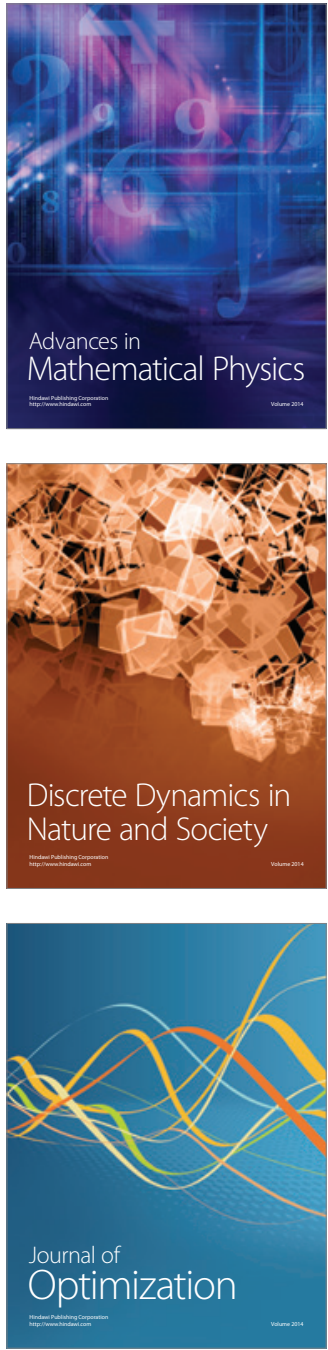